ORIGINAL ARTICLE

\title{
Monitoring of end tidal carbon dioxide and transcutaneous carbon dioxide during neonatal transport
}

D G Tingay, M J Stewart, C J Morley

See end of article for authors' affiliations

Arch Dis Child Fetal Neonatal Ed 2005;90:F523-F526. doi: 10.1136/adc.2004.064717

.....................

Correspondence to: Dr Tingay, Department of Neonatology, Royal Children's Hospital, Flemington Rd, Parkville, Victoria 3052, Australia; david.tingay@rch.org.au

Accepted 22 April 2005 Published Online First 29 April 2005
Objective: To assess the accuracy of measurements of end tidal carbon dioxide $\left(\mathrm{CO}_{2}\right)$ during neonatal transport compared with arterial and transcutaneous measurements.

Design: Paired end tidal and transcutaneous $\mathrm{CO}_{2}$ recordings were taken frequently during road transport of 21 ventilated neonates. The first paired $\mathrm{CO}_{2}$ values were compared with an arterial blood gas. The differences between arterial $\mathrm{CO}_{2}\left(\mathrm{PaCO}_{2}\right)$, transcutaneous $\mathrm{CO}_{2}\left(\mathrm{TCPCO}_{2}\right)$, and end tidal $\mathrm{CO}_{2}\left(\mathrm{PetCO}_{2}\right)$ were analysed. The Bland-Altman method was used to assess bias and repeatability.

Results: $\mathrm{PetCO}_{2}$ correlated strongly with $\mathrm{PaCO}_{2}$ and $\mathrm{TcPCO}_{2}$. However, $\mathrm{PetCO}_{2}$ underestimated $\mathrm{PaCO}_{2}$ at a clinically unacceptable level (mean (SD) $1.1(0.70) \mathrm{kPa}$ ) and did not trend reliably over time within individual subjects. The $\mathrm{PetCO}_{2}$ bias was independent of $\mathrm{PaCO}_{2}$ and severity of lung disease.

Conclusions: $\mathrm{PetCO}_{2}$ had an unacceptable under-recording bias. $\mathrm{TcPCO}_{2}$ should currently be considered the preferred method of non-invasive $\mathrm{CO}_{2}$ monitoring for neonatal transport.
C ontinuous non-invasive carbon dioxide $\left(\mathrm{CO}_{2}\right)$ monitoring has become an important bedside tool in neonatal receive full intensive care, but arterial blood gas monitoring is not possible. Assessing the efficacy of ventilation during neonatal transport is challenging. Continuous non-invasive $\mathrm{CO}_{2}$ monitoring has been shown to increase the likelihood of the patient arriving at the receiving hospital with a normal $\mathrm{pH}$ and partial pressure of $\mathrm{CO}_{2}\left(\mathrm{PaCO}_{2}\right)$.

Transcutaneous $\mathrm{CO}_{2}$ monitoring is the most commonly used non-invasive $\mathrm{CO}_{2}$ monitoring system in neonatal intensive care and has been shown to accurately predict $\mathrm{PaCO}_{2}$ and monitor $\mathrm{CO}_{2}$ trends. ${ }^{12}$ Calibrated transcutaneous partial pressure of carbon dioxide $\left(\mathrm{TcPCO}_{2}\right)$ has been shown to reliably approximate $\mathrm{PaCO}_{2}$ during neonatal transport and has been recommended as an alternative to frequent $\mathrm{PaCO}_{2}$ measurements. ${ }^{1}$ However, $\mathrm{TCPCO}_{2}$ devices are difficult to use, ${ }^{3}$ bulky, and weigh between 2 and $6 \mathrm{~kg}$, thus limiting their use during neonatal transport.

End tidal $\mathrm{CO}_{2}\left(\mathrm{PetCO}_{2}\right)$ monitors are lightweight and may indirectly monitor $\mathrm{PaCO}_{2}{ }^{5-8}$ Hence, $\mathrm{PetCO}_{2}$ may be more useful during transportation than $\mathrm{TCPCO}_{2}$ monitoring. Studies of $\mathrm{PetCO}_{2}$ monitoring in newborn infants have had mixed results, primarily because of the effects of ventilation perfusion mismatching on $\mathrm{PetCO}_{2}$, failure to reach an expiratory plateau during rapid respiratory rates, and the technical limitations of $\mathrm{PetCO}_{2}$ devices to interpret $\mathrm{CO}_{2}$ in small tidal volume states. ${ }^{25-12}$ Recent technological advances in $\mathrm{PetCO}_{2}$ monitoring, such as smaller sample volumes and sample cells calibrated to neonatal tidal volumes, have attempted to overcome the limitations. ${ }^{13}$ Some authors advocate $\mathrm{PetCO}_{2}$ as an acceptable method of approximation of $\mathrm{PaCO}_{2}$ trends in newborn infants. ${ }^{10}{ }^{14-16}$

The Newborn Emergency Transport Service of Victoria (NETS) is the largest neonatal transport service in Australasia. More than 900 infants a year are transported, with approximately one third ventilated. Monitoring of $\mathrm{TCPCO}_{2}$ and oxygen saturation have been standard practice for five years to indicate ventilation adequacy during transport, and previous unpublished data have shown a close correlation between $\mathrm{TCPCO}_{2}$ and $\mathrm{PaCO}_{2}$.
Arterial blood gases and $\mathrm{TCPCO}_{2}$ are commonly used to monitor ventilation. The aim of this study was to assess the accuracy and reliability of $\mathrm{PetCO}_{2}$ monitoring during neonatal transport.

\section{METHODS}

Ventilated infants requiring road transport to a level 3 neonatal intensive care unit during March to August 2002 were recruited if the paediatrician involved in the transport was specifically trained to use both $\mathrm{PetCO}_{2}$ and $\mathrm{TCPCO}_{2}$ monitors, an arterial catheter was being used, endotracheal tube position could be confirmed by chest radiograph before transport, and both $\mathrm{TCPCO}_{2}$ and $\mathrm{PetCO}_{2}$ monitoring could be started before the first arterial blood gas was measured by the NETS team. Because of the effects of barometric pressure on PetCO $_{2}$, infants transported by air were not studied. Informed parental consent was obtained for each infant before transport.

Infants were not studied if they were older than 28 days, had a capillary refill time of greater than two seconds, or $\mathrm{TCPCO}_{2}$ or $\mathrm{PetCO}_{2}$ readings could not be made or were lost during transport.

$\mathrm{TcPCO}_{2}$ was measured using the Microgas 7650 system (weight $5.6 \mathrm{~kg}$ ) with Combi.M sensor 82 (Linde, Basel, Switzerland) applied to the skin of the anterior chest or abdomen. The manufacturers report that the Combi.M sensor 82, once calibrated, will remain accurate for up to four hours at one site. $\mathrm{PetCO}_{2}$ was measured using a side stream end tidal analyser specifically designed for neonatal use (the Agilent Microstream system; Agilent Technologies, Andover, Massachusetts, USA); a result was the highest of five consecutive measurements. ${ }^{13}$ Arterial blood gases were analysed with the i-STAT portable clinical analyser (i-STAT Corporation, East Windsor, New Jersey, USA). Infants were ventilated using the Hoekloos Infant ventilator Mark 3

Abbreviations: $\mathrm{PaCO}_{2}$, arterial partial pressure of carbon dioxide; $\mathrm{TCPCO}_{2}$, transcutaneous partial pressure of carbon dioxide; $\mathrm{PetCO}_{2}$, end tidal partial pressure of carbon dioxide; NETS, Newborn Emergency Transport Service (Victoria); $\mathrm{PAO}_{2} / \mathrm{PaO}_{2}$ ratio, alveolar-arterial oxygen tension ratio 
Table 1 Characteristics of the 21 subjects enrolled in study

\begin{tabular}{|c|c|c|c|}
\hline & & Median & Range \\
\hline \multirow{4}{*}{\multicolumn{2}{|c|}{$\begin{array}{l}\text { Gestational age (weeks) } \\
\text { Birth weight (g) } \\
\text { Age at enrolment (hours) } \\
\text { Transportation time (minutes) }\end{array}$}} & 35 & $26-40$ \\
\hline & & 2260 & $930-4600$ \\
\hline & & 4.8 & $1.8-61.2$ \\
\hline & & 65 & $20-180$ \\
\hline & Mean (SD) & \multicolumn{2}{|l|}{ Range } \\
\hline $\mathrm{pH}$ & $7.32(0.12)$ & \multicolumn{2}{|l|}{$7.1-7.55$} \\
\hline $\mathrm{FlO}_{2}$ & $0.52(0.24)$ & \multicolumn{2}{|c|}{$0.21-1.0$} \\
\hline $\mathrm{PAO}_{2} / \mathrm{PaO}_{2}$ ratio & $0.85(1.3)$ & \multicolumn{2}{|c|}{$0.03-5.9$} \\
\hline \multicolumn{3}{|l|}{ Primary diagnosis } & Number \\
\hline \multicolumn{3}{|c|}{ Respiratory failure } & 15 \\
\hline \multicolumn{3}{|c|}{ Cyanotic heart disease } & 2 \\
\hline \multicolumn{3}{|c|}{$\begin{array}{l}\text { Persistent pulmonary hypertension of the } \\
\text { newborn }\end{array}$} & 1 \\
\hline \multicolumn{3}{|c|}{ Severe anaemia } & 1 \\
\hline \multicolumn{3}{|c|}{ Birth asphyxia } & 1 \\
\hline \multicolumn{3}{|c|}{ Multiple congenital abnormalities } & 1 \\
\hline
\end{tabular}

(Hoekloos, Amsterdam, Netherlands). The Australian Therapeutics Goods Administration has approved both devices for use in newborn infants. A specialist neonatal transport nurse and neonatal paediatrician escorted all infants.

After calibration of the $\mathrm{TCPCO}_{2}$ and $\mathrm{PetCO}_{2}$ monitors, paired $\mathrm{CO}_{2}$ measurements were recorded every 20 minutes, starting at stabilisation and continuing throughout the transport. The initial recordings were calibrated with a simultaneous $\mathrm{PaCO}_{2}$. The NETS team was not blinded to the $\mathrm{TcPCO}_{2}$ or $\mathrm{PetCO}_{2}$ values; any ventilator changes were based on the $\mathrm{TcPCO}_{2}$ or $\mathrm{PaCO}_{2}$ values.

The severity of each baby's lung disease was determined by calculating the alveolar to arterial oxygen tension ratio $\left(\mathrm{PAO}_{2} /\right.$ $\mathrm{PaO}_{2}$ ratio) where $\mathrm{PAO}_{2}=($ Barometric pressure -47$) \times$ $\left(\mathrm{FIO}_{2}-\mathrm{PaO}_{2}\right)$. Severe lung disease was defined as a $\mathrm{PAO}_{2} /$ $\mathrm{PaO}_{2}$ ratio $<0.3$. A $\mathrm{PAO}_{2} / \mathrm{PaO}_{2}$ ratio of $<0.3$ has been associated with less precision of $\mathrm{PetCO}_{2}$ measurements to estimate $\mathrm{PaCO}_{2} \cdot{ }^{15}$

The parents of all infants enrolled in the study provided written and signed informed consent for their infants to be transported by NETS and this involved specific consent to the use of all devices used in the study. This study was discussed with the Royal Women's Hospital Ethics in Human Research Committee. It was decided that formal ethics approval was not required as the above written informed consent adequately informed the parents and addressed the ethical issues of the study.

\section{Statistical analysis}

The differences between $\mathrm{PaCO}_{2}, \mathrm{TCPCO}_{2}$, and $\mathrm{PetCO}_{2}$ (expressed as $\mathrm{P}_{(\mathrm{a}-\mathrm{Tc})} \mathrm{CO}_{2}, \mathrm{P}_{(\mathrm{a}-\mathrm{Et})} \mathrm{CO}_{2}$, and $\mathrm{P}_{(\mathrm{Tc}-\mathrm{Et})} \mathrm{CO}_{2}$ respectively) were analysed using a Student's paired $t$ test, and their correlations were calculated. The Bland-Altman technique

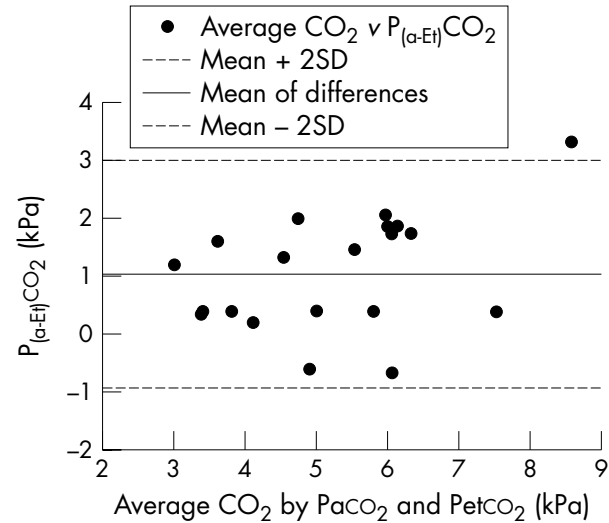

Figure 1 Bland-Altman plot of the difference between $\mathrm{PaCO}_{2}$ and $\mathrm{PetCO}_{2}\left(\mathrm{P}_{(\mathrm{a}-\mathrm{E} t)} \mathrm{CO}_{2}\right)$ against average $\mathrm{CO}_{2}$.

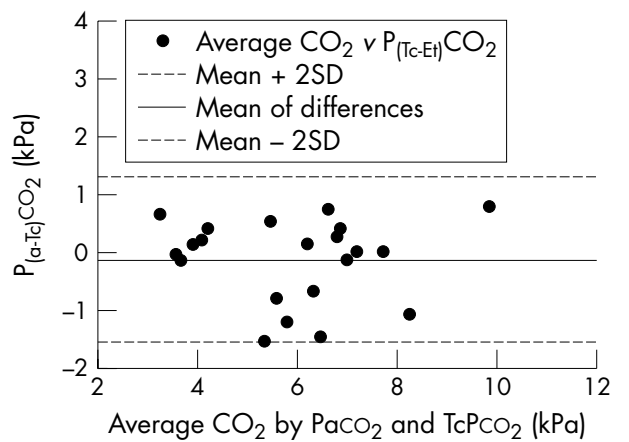

Figure 2 Bland-Altman plot of the difference between $\mathrm{PaCO}_{2}$ and $\mathrm{TCPCO}_{2}\left(\mathrm{P}_{(\mathrm{a}-\mathrm{Tc})} \mathrm{CO}_{2}\right)$ against average $\mathrm{CO}_{2}$.

was used to assess agreement and repeatability. ${ }^{17}$ A bias of less than $\pm 0.7 \mathrm{kPa}$ was considered clinically acceptable. Intrasubject $\mathrm{P}_{(\mathrm{Tc}-\mathrm{Et})} \mathrm{CO}_{2}$ variability over time was calculated.

\section{RESULTS}

Twenty six infants were enrolled, but five were excluded because the $\mathrm{PetCO}_{2}$ could not be continuously measured in three, both $\mathrm{TcPCO}_{2}$ and $\mathrm{PetCO}_{2}$ could not be measured in another, and in the fifth infant the initial blood gas was venous. Table 1 summarises the characteristics of the 21 infants. A total of $21 \mathrm{P}_{(\mathrm{a}-\mathrm{Tc})} \mathrm{CO}_{2}$ and $\mathrm{P}_{(\mathrm{a}-\mathrm{Et})} \mathrm{CO}_{2}$ differences and $82 \mathrm{P}_{(\mathrm{TC}-\mathrm{Et})} \mathrm{CO}_{2}$ differences (median recordings per subject 4.0 (range 2-10)) were calculated.

There was a linear relation between $\mathrm{PetCO}_{2}, \mathrm{PaCO}_{2}$, and $\mathrm{TCPCO}_{2}$. However, $\mathrm{PetCO}_{2}$ underestimated $\mathrm{PaCO}_{2}$ by an average of $1.04 \mathrm{kPa}$ (table 2, fig 1). Only $48 \%$ of $\mathrm{PetCO}_{2}$ recordings were within $1.0 \mathrm{kPa}$ of the paired $\mathrm{PaCO}_{2}$. The bias of the $\mathrm{PetCO}_{2}$ values was independent of the $\mathrm{PaCO}_{2}$.

$\mathrm{TcPCO}_{2}$ was closely related to $\mathrm{PaCO}_{2}$, with no significant difference between the two measurements (table 2). Two thirds of $\mathrm{TCPCO}_{2}$ readings were within $0.7 \mathrm{kPa}$ of the $\mathrm{PaCO}_{2}$,

Table 2 A comparison of $\mathrm{CO}_{2}(\mathrm{kPa})$ measured in three different ways

\begin{tabular}{lllll}
\hline & $\mathbf{n}$ & Mean (SD) & $95 \% \mathrm{Cl}$ & $\mathbf{p}$ Value \\
\hline $\mathrm{P}_{(\mathrm{a}-\mathrm{Tc})} \mathrm{CO}_{2}$ & 21 & $-0.13(0.71)$ & -0.46 to 0.19 & 0.4 \\
$\mathrm{P}_{(\mathrm{a}-\mathrm{Et})} \mathrm{CO}_{2}$ & 21 & $1.04(0.98)$ & 0.59 to 1.49 & $<0.001$ \\
$\mathrm{P}_{(\mathrm{Tc}-\mathrm{Et})} \mathrm{CO}_{2}$ & 82 & $-0.07(0.84)$ & -0.26 to 0.11 & 0.43 \\
\hline
\end{tabular}


and $81 \%$ of $\mathrm{TcPCO}_{2}$ readings were within $1 \mathrm{kPa}$ of the paired $\mathrm{PaCO}_{2}$. There was no significant change in the difference between $\mathrm{TcPCO}_{2}$ and $\mathrm{PaCO}_{2}$ as the $\mathrm{CO}_{2}$ level changed (fig 2 ).

When the initial $\mathrm{TcPCO}_{2}$ and $\mathrm{PetCO}_{2}$ values for each subject were calibrated to the original $\mathrm{PaCO}_{2}$, there was a closer relation between $\mathrm{PetCO}_{2}$ and $\mathrm{TcPCO}_{2}$ : $64 \%$ of $\mathrm{PetCO}_{2}$ values were within $0.7 \mathrm{kPa}$ of the paired $\mathrm{TcPCO}_{2}$ value (fig 3 ). Although the $\mathrm{P}_{(\mathrm{Tc}-\mathrm{Et})} \mathrm{CO}_{2}$ difference was not significant, the variability, as demonstrated by the Bland-Altman plot, was large (table 2, fig 3).

There was no significant relation between $\mathrm{PetCO}_{2}$ accuracy and severity of lung disease (table 3 ), although there was a non-significant trend towards $\mathrm{PetCO}_{2}$ values being more likely to reflect either $\mathrm{PaCO}_{2}$ or $\mathrm{TCPCO}_{2}$ in infants with a $\mathrm{PAO}_{2} / \mathrm{PaO}_{2}$ ratio $>0.3$. Muscle relaxation did not alter the reliability of $\mathrm{PetCO}_{2}$ to trend with $\mathrm{TcPCO}_{2}$.

\section{DISCUSSION}

This study shows that, in neonates requiring ventilation during transport, $\mathrm{TCPCO}_{2}$ monitoring more accurately reflected $\mathrm{PaCO}_{2}$ than $\mathrm{PetCO}_{2}$ monitoring. Furthermore, $\mathrm{PetCO}_{2}$ monitoring should be used with caution. Both $\mathrm{PetCO}_{2}$ and $\mathrm{TCPCO}_{2}$ were linearly related to $\mathrm{PaCO}_{2}$ and each other. However, a linear relation alone (or correlation coefficients-the method used in many of the previous reports) does not adequately describe the agreement between two clinical measurement techniques. ${ }^{2}{ }^{10}{ }^{18}$ Assessing agreement between two methods of clinical measurement is complex. The method described by Bland and Altman is a more informative technique for assessing agreement, reliability, and repeatability, and allows interpretation within a clinical context. ${ }^{17}$ With the use of this technique, $\mathrm{PetCO}_{2}$ was neither as precise nor reliable a method of assessing $\mathrm{PaCO}_{2}$ during the transport of ventilated neonates, whereas $\mathrm{TcPCO}_{2}$ provided a more reliable method. The degree of bias demonstrated between $\mathrm{PetCO}_{2}$ and $\mathrm{PaCO}_{2}(1.04 \mathrm{kPa})$ is clinically unacceptable.

Most of the infants in this study had mechanical ventilation instigated by the transport team; knowledge of any changes in the $\mathrm{CO}_{2}$ is essential for safe delivery of ventilation. Frequent $\mathrm{PaCO}_{2}$ measurements are not practical during neonatal transport; a reliable non-invasive indicator of $\mathrm{PaCO}_{2}$ is essential. Calibrated $\mathrm{TcPCO}_{2}$ is an acceptable surrogate for $\mathrm{PaCO}_{2}$ trends over time. Transcutaneous gas monitoring is an established and validated practice in neonatology. ${ }^{3}$ Newborn infants are particularly suited to transcutaneous monitoring because of their thin skin. Although proper use is dependent on appropriate training and placement, the only practical limitations are skin perfusion (which may be altered by vasoconstrictive agents,

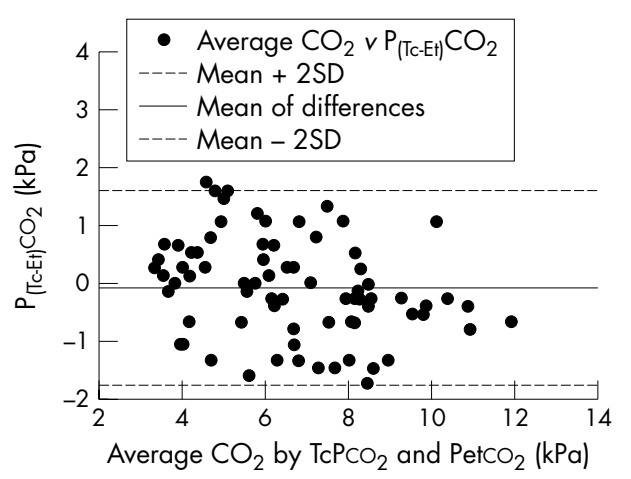

Figure 3 Bland-Altman plot of the difference between $\mathrm{TcPCO}_{2}$ and $\mathrm{PetCO}_{2}\left(\mathrm{P}_{(\mathrm{Tc}-\mathrm{Et})} \mathrm{CO}_{2}\right)$ against average $\mathrm{CO}_{2}$.

\section{What is already known on this topic}

- $\mathrm{TCPCO}_{2}$ has been shown to be an accurate and reliable method of indicating $\mathrm{PaCO}_{2}$ in neonates receiving intensive care

- Although measurement of $\mathrm{PetCO}_{2}$ can also indicate endotracheal tube position, in previous studies the ability to accurately reflect $\mathrm{PaCO}_{2}$ has been variable

\section{What this study adds}

- This study shows that $\mathrm{TcPCO}_{2}$ accurately reflects $\mathrm{PaCO}_{2}$ during neonatal transport, whereas $\mathrm{PetCO}_{2}$ underestimates $\mathrm{PaCO}_{2}$ by about $1.0 \mathrm{kPa}$, a clinically unacceptable difference

- $\mathrm{PetCO}_{2}$ was also unable to reliably reflect $\mathrm{TCPCO}_{2}$ over time, therefore this study supports the use of $\mathrm{TcPCO}_{2}$ as the preferred method of non-invasive $\mathrm{CO}_{2}$ monitoring during neonatal transport

hypovolaemia, and oedema) and the temperature produced by the device. The response time of $\mathrm{TcPCO}_{2}$ is too slow (3050 seconds) to allow monitoring of the respiratory pattern. ${ }^{19}$ $\mathrm{TCPCO}_{2}$ monitoring in neonatal transport has previously been evaluated and shown to result in improved ventilation on arrival at the receiving institution. ${ }^{120}$

Many authors have reported a good correlation between $\mathrm{PetCO}_{2}, \mathrm{TcPCO}_{2}$, and $\mathrm{PaCO}_{2}$ in newborn infants, but in only three studies that evaluated $\mathrm{PetCO}_{2}$ was the relation assessed using the Bland-Altman technique. ${ }^{14}{ }^{1521}$ Rozycki et al $^{14}$ described a mean (SD) $\mathrm{P}_{(\mathrm{a}-\mathrm{Et}) \mathrm{CO}_{2}}$ bias of $0.92(0.92) \mathrm{kPa}$ in 45 newborn infants receiving mechanical ventilation, with only $36.9 \%$ of $\mathrm{PetCO}_{2}$ values falling within $0.67 \mathrm{kPa}$ of the $\mathrm{PaCO}_{2}$. The authors concluded that despite the significant bias, $\mathrm{PetCO}_{2}$ provided a reliable estimate of $\mathrm{PaCO}_{2}$ trends. A similar mean $\mathrm{P}_{(\mathrm{a}-\mathrm{Et})} \mathrm{CO}_{2}$ difference of $0.91 \quad(0.68) \mathrm{kPa}$ was reported by Tobias and Meyer ${ }^{21}$ in 25 infants and toddlers (up to 48 months of age) receiving mechanical ventilation for respiratory failure; the $\mathrm{P}_{(\mathrm{a}-\mathrm{Tc})} \mathrm{CO}_{2}$ difference in this study was $0.31(0.18) \mathrm{kPa}$. Sivan et $\mathrm{al}^{15}$ obtained a clinically acceptable $\mathrm{P}_{(\mathrm{a}-\mathrm{Et})} \mathrm{CO}_{2}$ result, with a mean difference of $0.45(0.88) \mathrm{kPa}$ in a study involving 134 children (aged 2 days to 16 years) receiving mechanical ventilation. The mean $\mathrm{P}_{(\mathrm{a}-\mathrm{Tc})} \mathrm{CO}_{2}$ in this group was $-0.17(0.96) \mathrm{kPa}$. The $\mathrm{P}_{(\mathrm{a}-\mathrm{Tc})} \mathrm{CO}_{2}$ bias was related to skin perfusion but remained clinically acceptable. Primary diagnosis was not described in this study, nor was the proportion of the population who were newborn infants, making inference to the neonatal population difficult. Sivan and colleagues concluded that the degree of the $\mathrm{P}_{(\mathrm{a}-\mathrm{Et})} \mathrm{CO}_{2}$ bias was reduced in children with mild lung disease, as defined by a $\mathrm{PAO}_{2} / \mathrm{PaO}_{2}$ ratio of $>0.3$. In the cohort with severe lung disease, the mean $\mathrm{P}_{(\mathrm{a}-\mathrm{Et})} \mathrm{CO}_{2} 1.04$ (0.97) kPa was similar to our study.

Parenchymal lung disease with ventilation perfusion (V/Q) mismatching and a $\mathrm{PaO}_{2} / \mathrm{P}_{\mathrm{A}} \mathrm{O}_{2}<0.3$ is a feature of most causes of neonatal respiratory failure. During our study, only two infants did not require oxygen, and nearly all had parenchymal lung disease. Our study was not designed to assess the relation between degree of lung disease and $\mathrm{PetCO}_{2}$ accuracy.

$\mathrm{PetCO}_{2}$ monitoring has been validated in adult ventilated patients and healthy anaesthetised infants, but the infants in 
Table 3 Relation between $\mathrm{PetCO}_{2}$ values and severity of lung disease

\begin{tabular}{|c|c|c|c|c|c|c|}
\hline & \multicolumn{3}{|c|}{ Severe $(n=12)$} & \multicolumn{3}{|c|}{ Mild-moderate $(n=8)$} \\
\hline & Mean (SD) & $95 \% \mathrm{Cl}$ & p Value & Mean (SD) & $95 \% \mathrm{Cl}$ & $p$ Value \\
\hline $\mathrm{P}_{(\mathrm{a}-\mathrm{Et}) \mathrm{CO}_{2}}$ & $1.21(0.76)$ & 0.87 to 1.88 & $<0.001$ & $0.99(1.16)$ & -0.61 to 1.37 & 0.013 \\
\hline
\end{tabular}

our study had respiratory failure. ${ }^{10}{ }^{18} \mathrm{PetCO}_{2}$ is dependent on alveolar $\mathrm{CO}_{2}\left(\mathrm{PACO}_{2}\right)$ and the site of sampling. Non-uniform alveoli $\mathrm{CO}_{2}$ emptying patterns in patients with large ventilation perfusion mismatching result in $\mathrm{PACO}_{2}$ underestimating $\mathrm{PaCO}_{2}{ }^{5}{ }^{22}$

Technical limitations of end tidal analysis in patients with high rate, low tidal volume breathing would have contributed to the difference between $\mathrm{PetCO}_{2}$ and $\mathrm{PaCO}_{2}$. To account for the fresh inhaled gas admixture during proximal $\mathrm{PetCO}_{2}$ sampling, a minimum sampling flow rate of $150 \mathrm{ml} / \mathrm{min}$ is required. ${ }^{5}$ The end tidal analyser used in our study sampled at $50 \mathrm{ml} / \mathrm{min}$. Despite manufacturer assurances, this may have had an impact on our results. The response time of end tidal analysers must be less than the respiratory cycle. The response time of the end tidal analyser used was 190 milliseconds, which is adequate for the ventilation rates used during the study, although at high respiratory rates with a short expiratory time, all exhaled alveolar gas would not have migrated to a proximal end tidal sampling site on completion of each respiratory cycle. ${ }^{5}$

The relation between $\mathrm{TCPCO}_{2}$ and $\mathrm{PetCO}_{2}$ was not constant over time within individuals, even when both values were adjusted to $\mathrm{PaCO}_{2}$. In our opinion $\mathrm{PetCO}_{2}$ monitoring cannot be used to reliably monitor trends in $\mathrm{PaCO}_{2}$ over time in newborn infants with lung disease.

Despite our findings, $\mathrm{PetCO}_{2}$ monitoring may offer some benefits over $\mathrm{TCPCO}_{2}$ monitoring. Primarily the ability to rapidly and reliably confirm endotracheal tube position within the trachea, with either a capnograph or colorimetric end tidal $\mathrm{CO}_{2}$ indicator, is of great benefit within the noisy environment of neonatal transport. ${ }^{7}$ This study did not aim to assess the ability of $\mathrm{PetCO}_{2}$ or $\mathrm{TcPCO}_{2}$ to indicate endotracheal tube position. Inadvertent extubation is not a common occurrence in our transport population and did not occur in any of the neonates involved in this study. Further study is required to determine the role of $\mathrm{PetCO}_{2}$ in ensuring the endotracheal tube position during transport.

\section{CONCLUSIONS}

Owing to the bias of about $-1 \mathrm{kPa}$ and lack of consistency in measuring $\mathrm{PaCO}_{2}$ over time, $\mathrm{PetCO}_{2}$ cannot be recommended during neonatal transport to monitor ventilation. $\mathrm{TCPCO}_{2}$ monitoring was generally more precise, reliable, and agreed with $\mathrm{PaCO}_{2}$. $\mathrm{TcPCO}_{2}$ monitoring is the preferred method of non-invasive $\mathrm{CO}_{2}$ monitoring during neonatal transport.

\section{Authors' affiliations}

D G Tingay, M J Stewart, C J Morley, Neonatal Emergency Transport Service (Victoria), Royal Women's Hospital, Carlton, Victoria 3053, Australia

D G Tingay, M J Stewart, Department of Neonatology, Royal Children's Hospital, Parkville, Victoria 3052, Australia
M J Stewart, C J Morley, Department of Neonatology, Royal Women's Hospital

D G Tingay, C J Morley, Murdoch Childrens Research Institute, Parkville, Victoria 3052, Australia

Competing interests: none declared

\section{REFERENCES}

1 O'Connor TA, Grueber R. Transcutaneous measurement of carbon dioxide tension during long-distance transport of neonates receiving mechanical ventilation. J Perinatol 1998;18:189-92

2 McEvedy BA, McLeod ME, Mulera M et al. End-tidal, transcutaneous, and arterial $\mathrm{pCO}_{2}$ measurements in critically ill neonates: a comparative study. Anesthesiology 1988;69:112-16.

3 Huch A. Transcutaneous blood gas monitoring. Acta Anaesthesiol Scand Suppl 1995; 107:87-90.

4 Poets CF, Martin RJ. Noninvasive determinants of blood gases. In: Stocks J, Sly P, Tepper RS, et al, eds. Infant respiratory function testing. New York: Wiley-Liss, 1996:411-44.

5 Bhavani-Shankar K, Moseley H, Kumar AY, et al. Capnometry and anaesthesia. Can J Anaesth 1992;39:617-32.

6 Shankar KB, Moseley H, Kumar Y. Relationship between $\mathrm{PaCO}_{2}-\mathrm{PetCO}_{2}$ gradient and physiological dead space. Can J Anaesth 1991;38:1072-4.

7 Bhende MS, Karr VA, Wiltsie DC, et al. Evaluation of a portable infrared endtidal carbon dioxide monitor during pediatric interhospital transport. Pediatrics 1995;95:875-8.

8 Bhende MS, Thompson AE, Orr RA. Utility of an end-tidal carbon dioxide detector during stabilization and transport of critically ill children. Pediatrics 1992;89:1042-4.

9 Watkins AM, Weindling AM. Monitoring of end tidal $\mathrm{CO}_{2}$ in neonatal intensive care. Arch Dis Child 1987;62:837-9.

10 Badgwell JM, Heavner JE. End-tidal carbon dioxide pressure in neonates and infants measured by aspiration and flow-through capnography. J Clin Monit $1991 ; 7: 285-8$.

11 Hillier SC, Badgwell JM, McLeod ME, et al. Accuracy of end-tidal $\mathrm{PCO}_{2}$ measurements using a sidestream capnometer in infants and children ventilated with the Sechrist infant ventilator. Can J Anaesth 1990;37:318-21.

12 Rich GF, Sconzo JM. Continuous end-tidal $\mathrm{CO}_{2}$ sampling within the proximal endotracheal tube estimates arterial $\mathrm{CO}_{2}$ tension in infants. Can J Anaesth 1991;3:201-3.

13 Agilent $\mathrm{M} 3015 \mathrm{~A}$ Microstream $\mathrm{CO}_{2}$ measurement server extension data sheet. Andover, MA: Agilent Technologies Inc, 2000.

14 Rozycki HJ, Sysyn GD, Marshall MK, et al. Mainstream end-tidal carbon dioxide monitoring in the neonatal intensive care unit. Pediatrics 1998;101:648-53.

15 Sivan Y, Eldadah MK, Cheah TE, et al. Estimation of arterial carbon dioxide by end-tidal and transcutaneous $\mathrm{PCO}_{2}$ measurements in ventilated children. Pediatr Pulmonol 1992;12:153-7.

16 Rich GF, Sullivan MP, Adams JM. Is distal sampling of end-tidal $\mathrm{CO}_{2}$ necessary in small subjects? Anesthesiology 1990;73:265-8.

17 Bland JM, Altman DG. Statistical methods for assessing agreement between two methods of clinical measurement. Lancet 1986;1:307-10.

18 McDonald MJ, Montgomery VL, Cerrito PB, et al. Comparison of end-tidal $\mathrm{CO}_{2}$ and $\mathrm{PaCO}_{2}$ in children receiving mechanical ventilation. Pediatr Crit Care Med 2002;3:244-9.

19 Schibler A, Frey U. Role of lung function testing in the management of mechanically ventilated infants. Arch Dis Child Fetal Neonatal Ed 2002;87:F7-10.

20 Jacob J, Rose $D$, Stilson $M$, et al. Transcutaneous carbon dioxide monitoring during neonatal transport. Crit Care Med 1986;14:1050-2.

21 Tobias JD, Meyer DJ. Noninvasive monitoring of carbon dioxide during respiratory failure in toddlers and infants: end-tidal versus transcutaneous carbon dioxide. Anesth Analg 1997;85:55-8.

22 West J. Pulmonary pathophysiology: the essentials, 6th ed. Philadelphia: Lippincott Williams and Wilkins, 2003. 